\title{
Cetuximab versus bevacizumab following prior FOLFOXIRI and bevacizumab in postmenopausal women with advanced KRAS and BRAF wild-type colorectal cancer: a retrospective study
}

\author{
Chunlong Huang ${ }^{1+}$, Xiaoyuan $\mathrm{Gu}^{2+}$, Xianshang Zeng ${ }^{3}$, Baomin Chen ${ }^{1}$, Weiguang $\mathrm{Yu}^{3^{*}}$ and Meiji Chen ${ }^{4^{*}}$
}

\begin{abstract}
Background: An upgraded understanding of factors (sex/estrogen) associated with survival benefit in advanced colorectal carcinoma (CRC) could improve personalised management and provide innovative insights into antitumour mechanisms. The aim of this study was to assess the efficacy and safety of cetuximab (CET) versus bevacizumab (BEV) following prior 12 cycles of fluorouracil, leucovorin, oxaliplatin, and irinotecan (FOLFOXIRI) plus BEV in postmenopausal women with advanced KRAS and BRAF wild-type (wt) CRC.
\end{abstract}

Methods: Prospectively maintained databases were reviewed from 2013 to 2017 to assess postmenopausal women with advanced KRAS and BRAF wt CRC who received up to 12 cycles of FOLFOXIRI plus BEV inductive treatment, followed by CET or BEV maintenance treatment. The primary endpoints were overall survival (OS), progression-free survival (PFS), response rate. The secondary endpoint was the rate of adverse events (AEs).

Results: At a median follow-up of 27.0 months (IQR 25.1-29.2), significant difference was detected in median OS (17.7 months [95\% confidence interval [Cl], 16.2-18.6] for CET vs. 11.7 months [95\% Cl, 10.4-12.8] for BEV; hazard ratio [HR], $0.63 ; 95 \% \mathrm{Cl}, 0.44-0.89 ; p=0.007)$; Median PFS was 10.7 months ( $95 \% \mathrm{Cl}$, 9.8-11.3) for CET vs. 8.4 months (95\% Cl, 7.2-9.6) for BEV (HR, 0.67; 95\% Cl 0.47-0.94; $p=0.02)$. Dose reduction due to intolerable AEs occurred in 29 cases (24 [24.0\%] for CET vs. 5 [4.8\%] for BEV; $p<0.001$ ).

Conclusions: CET tends to be superior survival benefit when compared with BEV, with tolerated AEs.

Keywords: Cetuximab, Bevacizumab, Progression-free survival, Overall survival, Colorectal carcinoma

\footnotetext{
* Correspondence: 10211270007@fudan.edu.cn; chenmeiji_2016@163.com

${ }^{+}$Chunlong Huang and Xiaoyuan Gu contributed equally to this work.

${ }^{3}$ Department of Orthopaedics, The First Affiliated Hospital, Sun Yat-sen

University, No. 58, Zhongshan 2nd Road, Yuexiu District, Guangzhou 510080,

China

${ }^{4}$ Department of Pediatrics, The First Affiliated Hospital, Sun Yat-sen University, No. 58, Zhongshan 2nd Road, Yuexiu District, Guangzhou 510080, China

Full list of author information is available at the end of the article
}

(c) The Author(s). 2021 Open Access This article is licensed under a Creative Commons Attribution 4.0 International License, which permits use, sharing, adaptation, distribution and reproduction in any medium or format, as long as you give appropriate credit to the original author(s) and the source, provide a link to the Creative Commons licence, and indicate if changes were made. The images or other third party material in this article are included in the article's Creative Commons licence, unless indicated otherwise in a credit line to the material. If material is not included in the article's Creative Commons licence and your intended use is not permitted by statutory regulation or exceeds the permitted use, you will need to obtain permission directly from the copyright holder. To view a copy of this licence, visit http://creativecommons.org/licenses/by/4.0/ The Creative Commons Public Domain Dedication waiver (http://creativecommons.org/publicdomain/zero/1.0/) applies to the data made available in this article, unless otherwise stated in a credit line to the data. 


\section{Introduction}

Colorectal cancer (CRC), an aggressive disease, is historically the prominent cause of cancer-related deaths worldwide [1, 2]. Despite recent advances in CRC, the number of patients with advanced CRC has been increasing, raising concerns of the impact of advancedstage disease on survival and patient prognosis [3]. Treatment of patients with unresectable or metastatic $\mathrm{CRC}$ remains a challenge, and an unfavourable prognosis tends to be inevitable $[4,5]$. For patients with advanced $\mathrm{CRC}$, the combination schedules with fluorouracil, leucovorin, oxaliplatin, and irinotecan (FOLFOXIRI) plus either cetuximab (CET) or bevacizumab (BEV) have been proven to be effective according to previous clinical efficacy and safety profiles [6, 7]. Findings from the most recent randomized clinical trial [8] showed that no significant difference in overall survival (OS) between the addition of CET versus BEV to chemotherapy as initial treatment. In an open-label, randomized, phase 3 trial [9], the addition of CET to capecitabine, oxaliplatin, and BEV resulted in poor progression-free survival (PFS) and inferior quality of life. In another open-label, randomised, phase 3 trial [1], a noteworthy gain in OS and a positive but not significant trend of increased median PFS were observed.

The assessment of mutational status in the RAS and BRAF genes gained increasing importance for treatment of CRC [10]. For advanced CRC, BRAF V600E is mutated in $6-10 \%$ [11], and RAS gene (KRAS, NRAS) mutations occur in approximately 50\% [12]. In the current study, we identified the KRAS codon 12/13/61 and BRAF V600E wild-type (wt) mutations in $41.5 \%$ (204/ 492) of Chinese postmenopausal women. The mutation rate tends to be overestimated, because the initial raw data had included patients with BRAF mutations. For postmenopausal women with advanced KRAS and BRAF wt CRC, if disease progression occurs shortly after treatment, other treatment regimens with a distinct mechanism of action should be considered. However, little data regarding postmenopausal women with advanced KRAS and BRAF wt CRC or the comparison of CET versus $\mathrm{BEV}$ is available.

This retrospective cohort study was performed in postmenopausal women with advanced KRAS and BRAF wt $\mathrm{CRC}$, aiming to balance a favourable effect of survival benefit and adverse events (AEs) in these patients who underwent CET or BEV maintenance treatment following prior FOLFOXIRI plus BEV.

\section{Methods}

\section{Study population}

Data regarding general condition, drug delivery, and survival status for postmenopausal women with advanced CRC were retrieved from institutional prospectively maintained databases from Jan 3, 2013, to Jan 15, 2017. These data were coded in all participating organizations with a standard protocol using the International Classification of Diseases (ICD) v10.0 [13]. The cohort consisted of a total of 492 postmenopausal women who received up to 12 cycles of FOLFOXIRI plus BEV, followed by CET or BEV treatment. The main inclusion criteria were as follows: postmenopausal women with age $\geq 60$ years, amenorrhea for $\geq 6$ months, a histologically or clinically confirmed diagnosis of advanced CRC, KRAS and BRAF wt CRC, a measurable lesion per Response Evaluation Criteria in Solid Tumours (RECIST) v1.1 [14], adequate haematologic and renal functions, an Eastern Collaborative Oncology Group performance status (ECOG PS) of 0 or 1 . The main exclusion criteria were as follows: postmenopausal women with incomplete medical data or a discordant state of KRAS and BRAF mutations, a discontinuation or interruption initiated by non-drug itself in the CET or BEV regimen, a gastrointestinal perforation within the 12 months prior to treatment, brain metastasis, a significant bleeding event within the 6 months prior to treatment, severe circulatory diseases or organ failure, a history of medical conditions (i.e., hepatitis) affecting CET or BEV absorption, macrovascular invasion, uncontrolled metabolic diseases, a history of drug or alcohol abuse, a New York Heart Association classification of 3, serious infections, or vascular cognitive impairment [15].

\section{Study design and treatment}

A retrospective, multi-centre study was performed in which eligible postmenopausal women underwent up to 12 cycles of FOLFOXIRI plus BEV inductive treatment [16], followed by CET (intravenous $500 \mathrm{mg} / \mathrm{m} 2$ over $1 \mathrm{~h}, \mathrm{q} 2 \mathrm{w}$ ) [17] or $\mathrm{BEV}$ (intravenous dose of $5 \mathrm{mg} / \mathrm{kg}$ over half hour, q2w) maintenance treatment [18], without an off-treatment period until disease progression, intolerable AEs, withdrawal due to planned surgery, radiation therapy, or death.

\section{Mutational analysis of RAS-BRAF}

Genomic DNA was purified from formalin-fixed, paraffin-embedded samples of primary tumor tissue, and was extracted using the Qiamp FFPE DNA kit (Qiagen, Chatsworth, CA) following the manufacturer's instructions. Assessment for KRAS and BRAF mutational status was centrally performed for each individual included in the study by a pyrosequencing approach, as previously described [19]. All assessments were executed by PyroMark Q96 ID system (Qiagen, Germany) in the Molecular Laboratory, Sun Yat-sen University.

\section{Outcomes and assessments}

The primary endpoints were OS, PFS, and response rate. OS was defined as the interval from the beginning of 
maintenance to death from any cause or final follow-up. PFS was defined as the time from the beginning of maintenance to clinical or radiological progression or death from any cause, whichever occurred first. The response and progression were assessed in accordance with RECI ST v1.1. The secondary endpoint was the AE rate. The severity of AEs was graded using the US National Cancer Institute's Patient-Reported Outcomes Version of the Common Terminology Criteria for Adverse Events (PRO-CTCAE, V3.0, 20]. Tumour size was assessed using computed tomography or magnetic resonance imaging at each follow-up. Follow-up was done weekly during the first 1 month and then every 1 month thereafter. The median follow-up was calculated for the entire cohort.

\section{Statistical analysis}

Categorical variables were compared with Chi-Square tests; continuous variables were compared with Student t-test for normally distributed variables and MannWhitney U test for non-normally distributed variables. Median follow-up was estimated per the reverse KaplanMeier method. Survival was estimated using the KaplanMeier method. In the univariate and multivariate analyses, hazard ratios (HRs) and appropriate 95\% confidence intervals (CIs) were calculated using a Cox proportional hazard model. All statistical tests were twosided, and the significance level was set at 0.05. All data were analysed using SPSS software, v 26.0 (IBM Corp., Armonk, NY).

\section{Results}

\section{Comparison of baseline data}

In total, 492 individuals with advanced KRAS and BRAF wt CRC were reviewed, 288 of whom were deemed to be ineligible per the exclusion criteria, leaving 204 patients (CET: $n=100$, mean age 64.2 years [SD 9.5] and BEV: $n=$ $104,64.5$ years [SD 8.7]) who were eventually included for study eligibility (Fig. 1). Patient demographics and other characteristics from the data that were available at the time of our analyses are summarized in Table 1 . Median follow-up was 27.0 months (IQR 25.1-29.2).

\section{Comparison of efficacy}

At final follow-up, significant difference was detected in median OS (17.7 months [95\% CI, 16.2-18.6] for CET vs. 11.7 months [95\% CI, 10.4-12.8] for BEV). The difference in OS corresponded to an HR of 0.63 (95\% CI, $0.44-0.89$; $p=0.007$ ) (Fig. 2). Our analysis of PFS demonstrated that median PFS was significantly longer in the CET group than in the BEV group (10.7 months [95\% CI, 9.8-11.3] vs. 8.4 months [95\% CI, 7.2-9.6]; HR, 0.67, 95\% CI, 0.47-0.94; $p=0.02$ )(Fig. 3). Of 100 CET-treated individuals, $4(4.0 \%)$ had complete response and 67

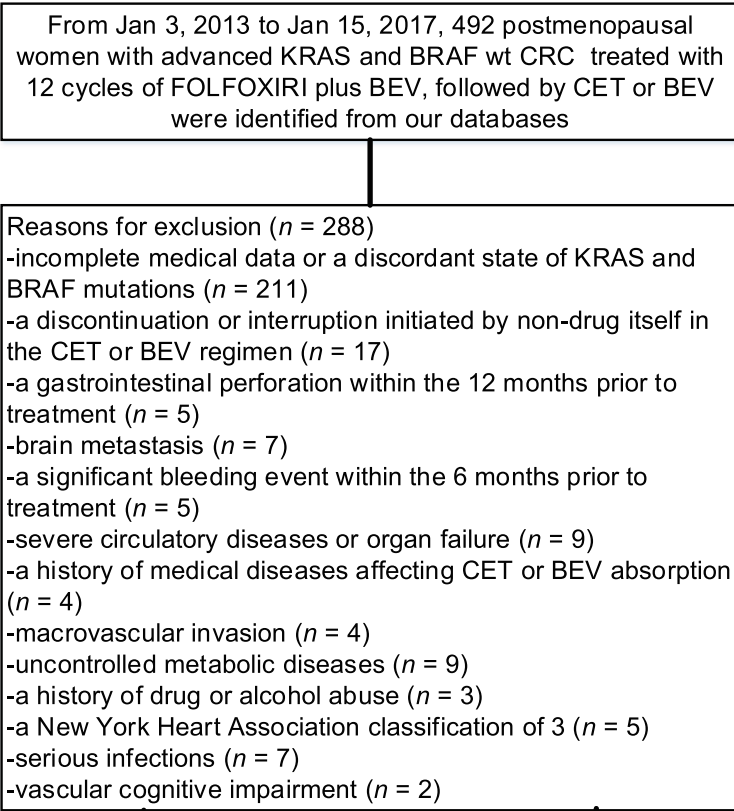

From Jan 3, 2013 to Jan 15, 2017, 492 postmenopausal women with advanced KRAS and BRAF wt CRC treated with 12 cycles of FOLFOXIRI plus BEV, followed by CET or BEV were identified from our databases

Reasons for exclusion $(n=288)$

-incomplete medical data or a discordant state of KRAS and BRAF mutations $(n=211)$

-a discontinuation or interruption initiated by non-drug itself in the CET or BEV regimen $(n=17)$

-a gastrointestinal perforation within the 12 months prior to treatment $(n=5)$

-brain metastasis $(n=7)$

-a significant bleeding event within the 6 months prior to

treatment $(n=5)$

-severe circulatory diseases or organ failure $(n=9)$

-a history of medical diseases affecting CET or BEV absorption $(n=4)$

-macrovascular invasion $(n=4)$

-uncontrolled metabolic diseases $(n=9)$

-a history of drug or alcohol abuse $(n=3)$

-a New York Heart Association classification of $3(n=5)$

-serious infections $(n=7)$

-vascular cognitive impairment $(n=2)$

Fig. 1 Flow diagram demonstrating the methods used for the identification of patients to retrospectively assess the efficacy and safety of cetuximab (CET) versus bevacizumab (BEV) following prior 12 cycles of FOLFOXIRI plus BEV in postmenopausal women with advanced KRAS and BRAF wild-type (wt) colorectal cancer (CRC)

(68.0\%) had partial response, for a response rate of 71.0\% (95\% CI, 63.1-77.4\%); 20 (19.0\%) had disease stabilization. The disease control rate was $91.0 \%$. Of 104 BEV-treated individuals, 2 (1.9\%) had complete response and $57(54.8 \%)$ had partial response, for a response rate of $56.7 \%$ (95\% CI, 61.7-72.8\%); 16 (15.4\%) had disease stabilization. The disease control rate was $75.0 \%$. Significant differences were detected in terms of the response rate $(p=0.034)$ and the control rate $(p<0.001)$ between groups.

\section{Adverse events}

With regard to the safety profile, the most frequent drug-related AEs at final follow-up are summarized in Table 2. Dose reduction occurred in 29 cases (24 [24.0\%] for CET vs. 5 [4.8\%] for BEV; $p<0.001)$ due to vomiting, nausea, or fatigue. AEs occurred earlier in the CET group, with nausea having a longer duration in the CET group than in the BEV group (median time to first occurrence 5 days [IQR 3-11] vs. 11 days [6-19, 21-29] for nausea, 30 days [16-78] vs. 33 days [27-84] for vomiting; median duration: 2.6 months [0.4-15.2] vs. 1.8 months [0.5-3.4] for nausea and 4 days [1-7] vs. 5 days [1-9] for vomiting, respectively). Skin AEs occurred in 26 cases $(12.7 \%)$ in each group, including 4 (2.0\%) with 
Table 1 Patient demographics and baseline characteristics

\begin{tabular}{|c|c|c|c|}
\hline Variable & CET $(n=100)$ & BEV $(n=104)$ & $P$-value \\
\hline Age at onset (years) & $64.2 \pm 9.5$ & $64.5 \pm 8.7$ & 0.231 \\
\hline CRC location ${ }^{\mathrm{a}}, \mathrm{n}(\%)$ & & & 0.331 \\
\hline Left & $52(52.0)$ & $47(45.2)$ & \\
\hline Right & $48(48.0)$ & $57(54.8)$ & \\
\hline Metastatic sites, n (\%) & & & 0.848 \\
\hline Intra-abdominal & $25(25.0)$ & $27(26.0)$ & \\
\hline Lung & $14(14.0)$ & $16(15.4)$ & \\
\hline Bone & $22(22.0)$ & $26(25.0)$ & \\
\hline Live & $25(25.0)$ & $17(16.3)$ & \\
\hline Brain & $7(7.0)$ & $9(8.7)$ & \\
\hline Other & $11(11.0)$ & 1413.5) & \\
\hline Serum lactate dehydrogenase level, n (\%) & & & 0.428 \\
\hline Normal $^{b}$ & $33(33.0)$ & $29(27.9)$ & \\
\hline Above normal & $67(67.0)$ & $75(72.1)$ & \\
\hline Portal vein invasion, $\mathrm{n}(\%)$ & & & 0.733 \\
\hline Yes & $67(67.0)$ & $72(69.2)$ & \\
\hline No & $33(33.0)$ & $32(30.8)$ & \\
\hline Duration of treatment (months) & $27.2 \pm 11.4$ & $27.3 \pm 12.5$ & 0.106 \\
\hline Hepatic encephalopathy, n (\%) & $0(0.0)$ & $0(0)$ & 1.000 \\
\hline ECOG PS, n (\%) & & & 0.860 \\
\hline 0 & $43(43.0)$ & $46(44.2)$ & \\
\hline 1 & $57(57.0)$ & $58(55.8)$ & \\
\hline Number of metastatic sites, n (\%) & & & 0.454 \\
\hline 3 & $13(13.0)$ & $20(19.2)$ & \\
\hline$>3$ & $72(72.0)$ & $68(65.4)$ & \\
\hline Unknown & $15(15.0)$ & $16(15.4)$ & \\
\hline
\end{tabular}

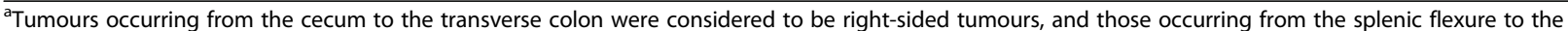

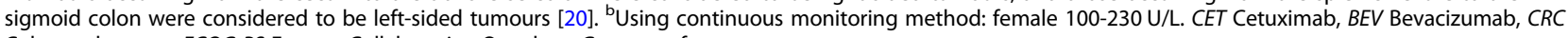
Colorectal cancer, ECOG PS Eastern Collaborative Oncology Group performance status

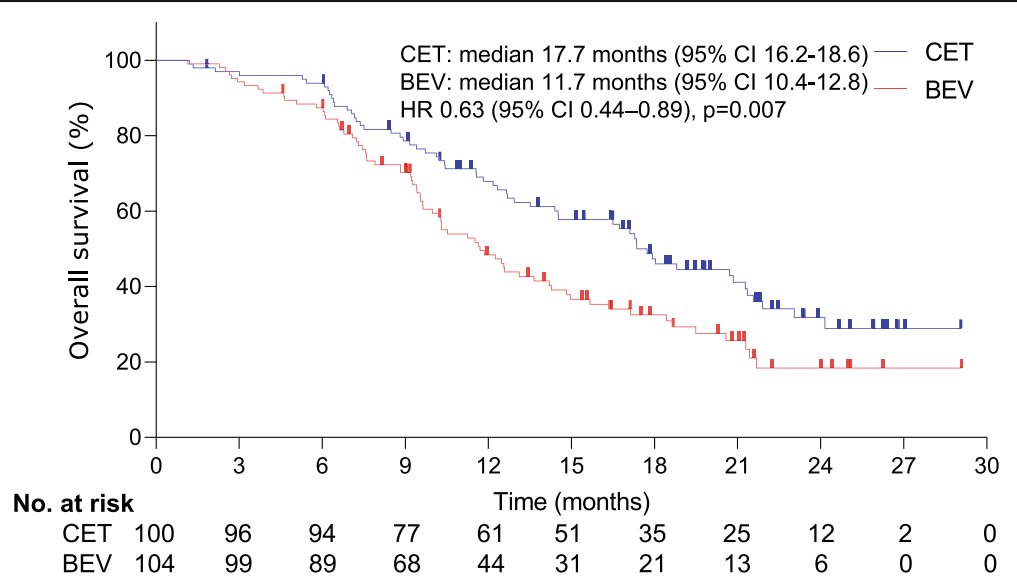

Fig. 2 Kaplan-Meier curves for overall survival. The median overall survival was 17.7 months ( $95 \% \mathrm{Cl}$, 16.2-18.6) for CET vs. 11.7 months (95\% Cl, 10.4-12.8) for BEV (HR, 0.63; 95\% Cl, 0.44-0.89; $p=0.007)$. Significant differences were detected in the overall survival between groups. *The hazard ratio was calculated using a Cox proportional hazards model, with age, the site of the primary tumour, the number of metastatic sites, serum lactate dehydrogenase level, portal vein invasion, duration of treatment, and the performance status as covariates and CET or BEV therapy as the time-dependent factor 


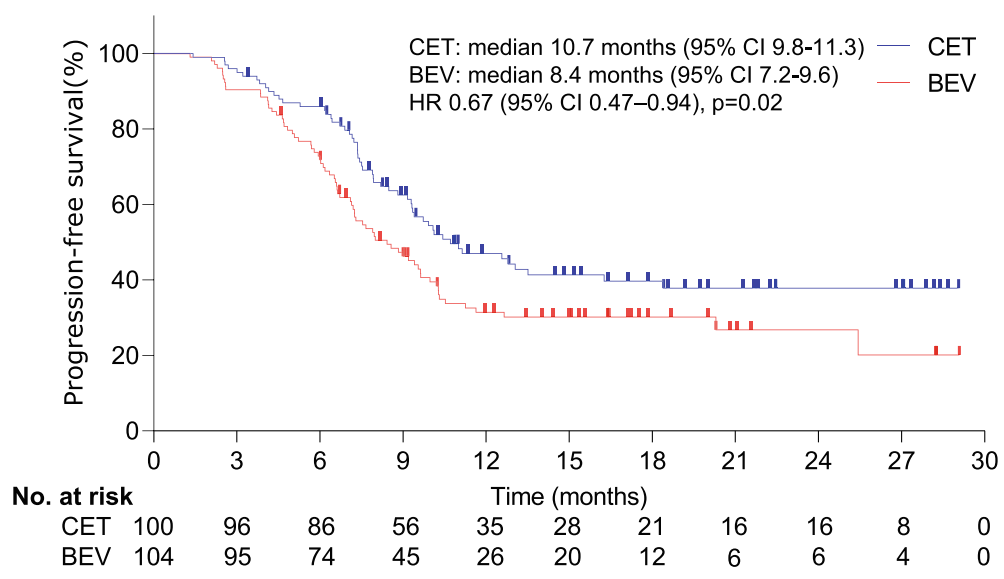

Fig. 3 Kaplan-Meier curves for progression-free survival. The median progression-free survival was 10.7 months (95\% Cl, 9.8-11.3) for CET vs. 8.4 months (95\% Cl, 7.2-9.6) for BEV (HR, 0.67; 95\% Cl 0.47-0.94; $p=0.02$ ). Statistically significant differences were detected in the progression-free survival between groups. ${ }^{*}$ The hazard ratio was calculated using a Cox proportional hazards model, with age, the site of the primary tumour, the number of metastatic sites, serum lactate dehydrogenase level, portal vein invasion, duration of treatment, and the performance status as covariates and CET or BEV therapy as the time-dependent factor

hepatic encephalopathy, of which 21 occurred during the first 4 months in the CET group and 5 occurred during the first 7 months in the BEV group. More than 2 grade 3/4 AEs in a single patient were reported in 23 (23\%) of the 100 cases in the CET group and in 12 $(11.5 \%)$ of the 104 cases in the BEV group $(p=0.030)$. The most frequent grade $4 \mathrm{AE}$ was diarrhoea (13 [13.0\%] cases in the CET group and 4 [5.4\%] cases in the BEV group, $p=0.018$ ).

\section{Discussion}

Our study demonstrates that CET maintenance treatment is inferiorly tolerated but has a moderate, if any,

Table 2 Comparison of the incidence of major drug-related grade 3 or 4 AEs between groups at final follow-up

\begin{tabular}{llll}
\hline AEs, $\boldsymbol{n}(\%)$ & CET $(\boldsymbol{n}=\mathbf{1 0 0})$ & BEV $(\boldsymbol{n}=\mathbf{1 0 4})$ & $\boldsymbol{P}$-value \\
\hline Skin & $21(21.0)$ & $5(4.8)$ & $0.001^{*}$ \\
Diarrhoea & $13(13.0)$ & $4(5.4)$ & $0.018^{*}$ \\
Anorexia & $5(5.0)$ & $1(1.0)$ & 0.088 \\
Vomiting & $7(7.0)$ & $1(1.0)$ & $0.026^{*}$ \\
Stomatitis & $5(5.0)$ & $3(2.9)$ & 0.436 \\
Fatigue & $9(9.0)$ & $2(1.9)$ & $0.025^{*}$ \\
Thrombocytopenia & $13(13.0)$ & $4(3.8)$ & $0.018^{*}$ \\
Dysphonia & $3(3.0)$ & $4(3.8)$ & 0.740 \\
Proteinuria & $10(10.0)$ & $3(2.9)$ & $0.038^{*}$ \\
Nausea & $8(8.0)$ & $2(1.9)$ & $0.044^{*}$ \\
Hypoalbuminemia & $8(8.0)$ & $7(6.7)$ & 0.728 \\
Peripheral oedema & $7(7.0)$ & $8(7.7)$ & 0.850 \\
Hepatic encephalopathy & $3(3.0)$ & $5(4.8)$ & 0.506 \\
$\geq 2$ AEs in one patient & $23(22.0)$ & $12(11.5)$ & $0.030^{*}$ \\
\hline
\end{tabular}

*Statistically significant. AEs Adverse events, CET Cetuximab, BEV Bevacizumab survival benefit when compared with BEV maintenance treatment. The superiority of CET over BEV in the clinical setting tends to be positive, which does not deviate from prior studies involving patients with advanced KRAS and BRAF wt CRC $[8,22,23]$.

Our findings align with those obtained from published studies $[2,24]$ and may provide a confirmation that CET tends to improve survival benefit for postmenopausal women with advanced KRAS and BRAF wt CRC. Furthermore, whereas previous trials failed to focus on the differences in the genders and oestrogen in patients with advanced KRAS and BRAF wt CRC, the current study provides an analysis of the postmenopausal population. Previous pooled analysis [25] (phase III CRYSTAL [26] and phase II OPUS $[10,27]$ trials) involving 730 patients with KRAS /BRAF wt metastatic CRC showed that the median OS was 24.8 months (95\%CI, 22.1-27.0) for CET plus chemotherapy versus 21.1 months $(95 \% \mathrm{CI}, 19.5-$ 23.6) for chemotherapy alone (HR, 0.84; $95 \%$ CI, $0.71-$ $1.00 ; p=0.048)$; the median PFS was 10.9 months $(95 \% \mathrm{CI}$, 9.2-11.9) for CET plus chemotherapy versus 7.7 months (95\%CI 7.4-9.0) for chemotherapy alone (HR, 0.64; 95\% CI, $0.52-0.79 ; p<0.001$ ), and confirms the benefit of adding CET to first-line chemotherapy. Consistent with our findings, a distinct separation of OS curves favouring the continuation of CET rather than the switch to BEV was detected. Consistent results have also been reported in the CECOG/CORE 1.2.002 study [28], which showed that RAS mutations (median OS, 16.3 months) or BRAF mutations (median OS, 11.7 months) is associated with poor outcome in metastatic CRC patients. The OS or PFS of adding CET to chemotherapeutic regimens for patients of differing genetic backgrounds remains heterogeneous according to a specific patient population, 
metastatic sites, or different treatment regimens in different regions $[5,8,10,29]$.

In a randomized clinical trial [8], 1137 enrolled patients with KRAS wt advanced or metastatic CRC who were treated with first-line chemotherapy combined with CET or BEV showed that the median OS was 30.0 months in the CET-chemotherapy group and 29.0 months in the BEV-chemotherapy group ( $\mathrm{HR}, 0.88 ; 95 \% \mathrm{CI}, 0.77$ to 1.01 ); no significant difference in OS was observed between groups. Why these similar regimens translated into different gains in OS is bewildering. Potential explanations for the worse-than-expected OS performance could be the choice of the study population, or the way in which oestrogen affects advanced CRC $[30,31]$. In the present study, the choice of CET or BEV as a monotherapy, rather than its combination with chemotherapy, could have an impact on OS performance. Based on various tyrosine kinase inhibitors that have been tested in several phase II trials $[32,33]$ of targeted therapies for advanced CRC, the treatments did not improve clinical outcomes or failed to meet the primary endpoints; thus, the results appeared to be somewhat discouraging, at best [6]. An interaction between subgroups tends to be associated with inferior survival benefit in patients with advanced CRC [25, 34].

Frequent debate has occurred over the influence of postmenopausal women who tend to be even less responsive to the present treatment regimen [35, 36]. There is also a paucity of survival data in the previous trials [22, 23, 37] for female patients with treatmentnaive advanced CRC. Nevertheless, the survival benefit with CET appears to be encouraging even when compared with other targeted therapies in patients with advanced CRC [25, 32]. Despite a definitive separation of survival curves, approving the continuation of CET rather than the switch to $\mathrm{BEV}$, the current population was limited to postmenopausal women. Furthermore, although a strong adherence to the protocol regimen was reintroduced in the majority of patients with advanced $\mathrm{CRC}$, the relationship between disease progression and survival in advanced CRC may be confounded due to the critical risk of death as a result of impaired hepatic function [38, 39]. Undeniably, if progression occurs shortly after treatment cessation, additional protocol regimens utilizing compounds with a diverse mechanism of action should be promoted [25, 38].

As predicted, the safety profiles of CET and BEV were manageable. In light of our findings, $54 \%$ of cases underwent more than 2 drug-related AEs, the majority of which were grade 1 to 2 . The frequency of AEs was in line with the known safety profiles of CET and BEV. $\mathrm{BEV}$ seems to be safer than CET. The more frequent grade 3 or $4 \mathrm{AEs}$ in response to CET than to $\mathrm{BEV}$ were mainly attributed to skin AEs, which was generally controllable.
Several limitations should be acknowledged in this study. First, the retrospective nature has inherent limitations, and potential confounding variables (i.e., sleep quality and underlying diseases) could not be processed very well. Second, generalisability is lacking because the study population involved only postmenopausal women with advanced CRC. Replication of these findings in a prospective cohort trial is required to clarify the generalisability of results. Third, our data were gathered from different institutions, in which diagnostic procedures may be different. Nonetheless, the multicentre data were merged using standardised methods, which provides reliability across these institutions.

\section{Conclusion}

The results reported in the current study might echo a growing body of evidence showing that for postmenopausal women with advanced KRAS and BRAF wt CRC treated with prior 12 cycles of FOLFOXIRI plus BEV, CET appears to be inferiorly tolerated but has a moderate, if any, survival benefit compared with BEV. Future clinical trials of the efficacy and safety of CET versus $\mathrm{BEV}$ in an analogous setting might benefit from stratification of analyses according to the study population.

\section{Abbreviations \\ CET: Cetuximab; BEV: Bevacizumab; CRC: Colorectal cancer; IQR: Interquartile range; PFS: Progression-free survival; OS: Overall survival; AEs: Adverse events; Cl: Confidence interval; HR: Hazard ratio; FOLFOXIRI: Fluorouracil, leucovorin, oxaliplatin, and irinotecan; ICD: International Classification of Diseases; RECI ST: Response Evaluation Criteria in Solid Tumours; ECOG PS: Eastern Collaborative Oncology Group performance status; PRO-CTCAE: Patient- reported outcomes version of the common terminology criteria for adverse events; SD: Standard deviation}

\section{Acknowledgments}

Not applicable.

\section{Authors' contributions}

$\mathrm{CH}$ : Planning and study design, data collection, and writing-initial draft. XG and MC: Statistical analysis and writing-final revision. XZ, BC, and WY: Planning and study design. All authors have read and approve the final version.

\section{Funding}

This work received no specific grant from any funding agency in the public, commercial, or not-for-profit sectors.

\section{Availability of data and materials}

The datasets used and/or analysed during the current study are available from the corresponding author on reasonable request.

\section{Ethics approval and consent to participate}

The study protocol was approved by the Institutional Ethics Committee, Helsinki committee of the First Affiliated Hospital, Sun Yat-sen University; the approval number is 11922-43. Written informed consent was waived by our Institutional Ethics Committee.

Consent for publication

Not applicable.

Competing interests

The authors declare that they have no competing interests. 


\section{Author details}

'Department of Hepatobiliary Surgery, The First Affiliated Hospital, Sun Yat-sen University, No. 58, Zhongshan 2nd Road, Yuexiu District, Guangzhou 510080, China. ${ }^{2}$ Department of Oncology, Shibei Hospital of Shanghai, No. 4500, Goughexin Road, Jing' an District, Shanghai 200443, China. ${ }^{3}$ Department of Orthopaedics, The First Affiliated Hospital, Sun Yat-sen University, No. 58, Zhongshan 2nd Road, Yuexiu District, Guangzhou 510080, China. ${ }^{4}$ Department of Pediatrics, The First Affiliated Hospital, Sun Yat-sen University, No. 58, Zhongshan 2nd Road, Yuexiu District, Guangzhou 510080, China.

\section{Received: 25 August 2020 Accepted: 26 December 2020} Published online: 07 January 2021

\section{References}

1. Heinemann V, von Weikersthal LF, Decker T, Kiani A, Vehling-Kaiser U, AlBatran SE, Heintges T, Lerchenmuller C, Kahl C, Seipelt G, Kullmann F, Stauch M, Scheithauer W, Hielscher J, Scholz M, Muller S, Link H, Niederle N, Rost A, Hoffkes HG, Moehler M, Lindig RU, Modest DP, Rossius L, Kirchner T, Jung A, Stintzing S. FOLFIRI plus cetuximab versus FOLFIRI plus bevacizumab as first-line treatment for patients with metastatic colorectal cancer (FIRE-3): a randomised, open-label, phase 3 trial. Lancet Oncol. 2014; 15(10):1065-75.

2. Stintzing $S$, Modest DP, Rossius L, Lerch MM, von Weikersthal LF, Decker T, Kiani A, Vehling-Kaiser U, Al-Batran SE, Heintges T, Lerchenmuller C, Kahl C, Seipelt G, Kullmann F, Stauch M, Scheithauer W, Held S, Giessen-Jung C, Moehler M, Jagenburg A, Kirchner T, Jung A, Heinemann V, Investigators F. FOLFIRI plus cetuximab versus FOLFIRI plus bevacizumab for metastatic colorectal cancer (FIRE-3): a post-hoc analysis of tumour dynamics in the final RAS wild-type subgroup of this randomised open-label phase 3 trial. Lancet Oncol. 2016;17(10):1426-34.

3. Brule SY, Jonker DJ, Karapetis CS, O'Callaghan CJ, Moore MJ, Wong R, Tebbutt NC, Underhill C, Yip D, Zalcberg JR, Tu D, Goodwin RA. Location of colon cancer (right-sided versus left-sided) as a prognostic factor and a predictor of benefit from cetuximab in NCIC CO.17. Eur J Cancer. 2015; 51(11):1405-14.

4. Crosby T, Hurt CN, Falk S, Gollins S, Mukherjee S, Staffurth J, Ray R, Bashir N, Bridgewater JA, Geh Jl, Cunningham D, Blazeby J, Roy R, Maughan T, Griffiths $\mathrm{G}$. Chemoradiotherapy with or without cetuximab in patients with oesophageal cancer (SCOPE1): a multicentre, phase 2/3 randomised trial. Lancet Oncol. 2013;14(7):627-37.

5. De Roock W, Claes B, Bernasconi D, De Schutter J, Biesmans B, Fountzilas G, Kalogeras KT, Kotoula V, Papamichael D, Laurent-Puig P, Penault-Llorca F, Rougier P, Vincenzi B, Santini D, Tonini G, Cappuzzo F, Frattini M, Molinari F, Saletti P, De Dosso S, Martini M, Bardelli A, Siena S, Sartore-Bianchi A, Tabernero J, Macarulla T, Di Fiore F, Gangloff AO, Ciardiello F, Pfeiffer P, Qvortrup C, Hansen TP, Van Cutsem E, Piessevaux H, Lambrechts D, Delorenzi M, Tejpar S. Effects of KRAS, BRAF, NRAS, and PIK3CA mutations on the efficacy of cetuximab plus chemotherapy in chemotherapyrefractory metastatic colorectal cancer: a retrospective consortium analysis. Lancet Oncol. 2010;11(8):753-62.

6. Cainap C, Qin SK, Huang WT, Chung IJ, Pan HM, Cheng Y, Kudo M, Kang YK, Chen PJ, Toh HC, Gorbunova V, Eskens F, Qian J, McKee MD, Ricker JL, Carlson DM, El-Nowiem S. Linifanib versus Sorafenib in patients with advanced hepatocellular carcinoma: results of a randomized phase III trial. J Clin Oncol. 2015;33(2):172-U77.

7. Lencioni R, Llovet JM, Han GH, Tak WY, Yang JM, Guglielmi A, Paik SW, Reig M, Kim DY, Chau GY, Luca A, del Arbol LR, Leberre MA, Niu W, Nicholson K, Meinhardt G, Bruix J. Sorafenib or placebo plus TACE with doxorubicineluting beads for intermediate stage HCC: the SPACE trial. J Hepatol. 2016; 64(5):1090-8.

8. Venook AP, Niedzwiecki D, Lenz HJ, Innocenti F, Fruth B, Meyerhardt JA, Schrag D, Greene C, O'Neil BH, Atkins JN, Berry S, Polite BN, O'Reilly EM, Goldberg RM, Hochster HS, Schilsky RL, Bertagnolli MM, El-Khoueiry AB, Watson P, Benson A, Mulkerin DL, Mayer RJ, Blanke C. Effect of First-Line Chemotherapy Combined With Cetuximab or Bevacizumab on Overall Survival in Patients With KRAS Wild-Type Advanced or Metastatic Colorectal Cancer A Randomized Clinical Trial. JAMA. 2017;317(23):2392-401.

9. Tol J, Koopman M, Cats A, Rodenburg CJ, Creemers GJM, Schrama JG, Erdkamp FLG, Vos AH, van Groeningen CJ, Sinnige HAM, Richel DJ, Voest EE, Dijkstra JR, Vink-Borger ME, Antonini NF, Mol L, van Krieken J, Dalesio O,
Punt CJA. Chemotherapy, Bevacizumab, and Cetuximab in metastatic colorectal Cancer. N Engl J Med. 2009;360(6):563-72

10. Cremolini C, Antoniotti C, Lonardi S, Aprile G, Bergamo F, Masi G, Grande R, Tonini G, Mescoli C, Cardellino GG, Coltelli L, Salvatore L, Corsi DC, Lupi C, Gemma D, Ronzoni M, Dell'Aquila E, Marmorino F, Di Fabio F, Mancini ML, Marcucci L, Fontanini G, Zagonel V, Boni L, Falcone A. Activity and Safety of Cetuximab Plus Modified FOLFOXIRI Followed by Maintenance With Cetuximab or Bevacizumab for RAS and BRAF Wild-type Metastatic Colorectal Cancer A Randomized Phase 2 Clinical Trial. Jama Oncol. 2018; 4(4):529-36.

11. Schirripa M, Bergamo F, Cremolini C, Casagrande M, Lonardi S, Aprile G, Yang D, Marmorino F, Pasquini G, Sensi E, Lupi C, De Maglio G, Borrelli N, Pizzolitto S, Fasola G, Bertorelle R, Rugge M, Fontanini G, Zagonel V, Loupakis F, Falcone A. BRAF and RAS mutations as prognostic factors in metastatic colorectal cancer patients undergoing liver resection. $\mathrm{Br} J$ Cancer. 2015;112(12):1921-8

12. Morris VK, San Lucas FA, Overman MJ, Eng C, Morelli MP, Jiang ZQ, Luthra R, Meric-Bernstam F, Maru D, Scheet P, Kopetz S, Vilar E. Clinicopathologic characteristics and gene expression analyses of non-KRAS 12/13, RASmutated metastatic colorectal cancer. Ann Oncol. 2014;25(10):2008-14.

13. Outland B, Newman MM, William MJ. Health Policy Basics: Implementation of the International Classification of Disease, 10th Revision. Ann Intern Med. 2015;163(7):554.

14. Therasse P, Arbuck SG, Eisenhauer EA, Wanders J, Kaplan RS, Rubinstein L, Verweij J, Van Glabbeke M, van Oosterom AT, Christian MC, Gwyther SG. New guidelines to evaluate the response to treatment in solid tumors. J Natl Cancer Inst. 2000;92(3):205-16.

15. Kopchak O. Efficacy of citicoline in the treatment of patients with vascular cognitive impairment. J Neurol. 2010;257:S128.

16. Cremolini C, Loupakis F, Antoniotti C, Lupi C, Sensi E, Lonardi S, Mezi S, Tomasello G, Ronzoni M, Zaniboni A, Tonini G, Carlomagno C, Allegrini G, Chiara S, D'Amico M, Granetto C, Cazzaniga M, Boni L, Fontanini G, Falcone A. FOLFOXIRI plus bevacizumab versus FOLFIRI plus bevacizumab as firstline treatment of patients with metastatic colorectal cancer: updated overall survival and molecular subgroup analyses of the open-label, phase 3 TRIBE study. Lancet Oncol. 2015;16(13):1306-15.

17. Saridaki Z, Androulakis N, Vardakis N, Vamvakas L, Kabouraki E, Kalbakis K, Hatzidaki D, Voutsina A, Mavroudis D, Georgoulias V, Souglakos J. A triplet combination with irinotecan (CPT-11), oxaliplatin (LOHP), continuous infusion 5-fluorouracil and leucovorin (FOLFOXIRI) plus cetuximab as firstline treatment in KRAS wt, metastatic colorectal cancer: a pilot phase II trial. Br J Cancer. 2012;107(12):1932-7.

18. Cremolini C, Loupakis F, Masi G, Lonardi S, Granetto C, Mancini ML, Chiara S, Moretto R, Rossini D, Vitello S, Allegrini G, Tonini G, Bergamo F, Tomasello G, Ronzoni M, Buonadonna A, Bustreo S, Barbara C, Boni L, Falcone A. FOLFOXIRI or FOLFOXIRI plus bevacizumab as first-line treatment of metastatic colorectal cancer: a propensity score-adjusted analysis from two randomized clinical trials. Ann Oncol. 2016;27(5):843-9.

19. Fornaro L, Lonardi S, Masi G, Loupakis F, Bergamo F, Salvatore L, Cremolini C, Schirripa M, Vivaldi C, Aprile G, Zaniboni A, Bracarda S, Fontanini G, Sensi E, Lupi C, Morvillo M, Zagonel V, Falcone A. FOLFOXIRI in combination with panitumumab as first-line treatment in quadruple wild-type (KRAS, NRAS, HRAS, BRAF) metastatic colorectal cancer patients: a phase II trial by the Gruppo Oncologico Nord Ovest (GONO). Ann Oncol. 2013;24(8):2062-7.

20. Meguid RA, Slidell MB, Wolfgang CL, Chang DC, Ahuja N. Is there a difference in survival between right- versus left-sided colon cancers? Ann Surg Oncol. 2008;15(9):2388-94.

21. Dueck AC, Mendoza TR, Mitchell SA, Reeve BB, Castro KM, Rogak $L$, Atkinson TM, Bennett AV, Denicoff AM, O'Mara AM, Li YL, Clauser SB, Bryant DM, Bearden JD, Gillis TA, Harness JK, Siegel RD, Paul DB, Cleeland CS, Schrag D, Sloan JA, Abernethy AP, Bruner DW, Minasian LM, Basch E. Natl Canc Inst PROCSG. Validity and reliability of the US National Cancer Institute's patient-reported outcomes version of the common terminology criteria for adverse events (PRO-CTCAE). Jama Oncol. 2015;1(8):1051-9.

22. Ye LC, Liu TS, Ren L, Wei Y, Zhu DX, Zai SY, Ye QH, Yu YY, Xu B, Qin XY, Xu JM. Randomized controlled trial of Cetuximab plus chemotherapy for patients with KRAS wild-type Unresectable colorectal liver-limited metastases. J Clin Oncol. 2013;31(16):1931-8.

23. Zakari A, Gian VG, Meluch AA, Peyton JD, Waterhouse DM, Lipman AJ, Boccia RV, Jones SF, Bendell JC. Phase II study of FOLFOXIRI plus panitumumab (pmab) followed by evaluation for resection, in patients (pts) 
with metastatic KRAS wild-type colorectal cancer (mCRC) with liver metastases only. J Clin Oncol. 2014;32(15):e14552.

24. Feliu J, Safont MJ, Salud A, Losa F, Garcia-Giron C, Bosch C, Escudero P, Lopez R, Madronal C, Bolanos M, Gil M, Llombart A, Castro-Carpeno J, Gonzalez-Baron M. Capecitabine and bevacizumab as first-line treatment in elderly patients with metastatic colorectal cancer. Br J Cancer. 2010;102(10): 1468-73.

25. Bokemeyer C, Van Cutsem E, Rougier P, Ciardiello F, Heeger S, Schlichting M, Celik I, Kohne CH. Addition of cetuximab to chemotherapy as first-line treatment for KRAS wild-type metastatic colorectal cancer: pooled analysis of the CRYSTAL and OPUS randomised clinical trials. Eur J Cancer. 2012; 48(10):1466-75.

26. Van Cutsem E, Kohne CH, Hitre E, Zaluski J, Chien CRC, Makhson A, D'Haens G, Pinter T, Lim R, Bodoky G, Roh JK, Folprecht G, Ruff P, Stroh C, Tejpar S, Schlichting M, Nippgen J, Rougier P. Cetuximab and chemotherapy as initial treatment for metastatic colorectal Cancer. N Engl J Med. 2009;360(14): 1408-17.

27. Bokemeyer C, Bondarenko I, Makhson A, Hartmann JT, Aparicio J, de Braud F, Donea S, Ludwig H, Schuch G, Stroh C, Loos AH, Zubel A, Koralewski P. Fluorouracil, Leucovorin, and Oxaliplatin with and without Cetuximab in the first-line treatment of metastatic colorectal Cancer. J Clin Oncol. 2009;27(5): 663-71.

28. Kaczirek K, Ciuleanu TE, Vrbanec D, Marton E, Messinger D, Liegl-Atzwanger B, Wrba F, Knittelfelder R, Lindner E, Zielinski CC, Streubel B, Brodowicz T. FOLFOX4 Plus Cetuximab for Patients With Previously Untreated Metastatic Colorectal Cancer According to Tumor RAS and BRAF Mutation Status: Updated Analysis of the CECOG/CORE 1.2.002 Study. Clin Colorectal Cancer. 2015;14(2):91-8.

29. Bokemeyer C, Bondarenko I, Hartmann JT, de Braud F, Schuch G, Zubel A, Celik I, Schlichting M, Koralewski P. Efficacy according to biomarker status of cetuximab plus FOLFOX-4 as first-line treatment for metastatic colorectal cancer: the OPUS study. Ann Oncol. 2011;22(7):1535-46.

30. Tsilidis KK, Allen NE, Key TJ, MA SJ, Bakken K, Berrino F, Fournier A, Lund E, Overvad K, Olsen A, Tjonneland A, Byrnes G, Chajes V, Rinaldi S, BoutronRuault MC, Clavel-Chapelon F, Chang-Claude J, Kaaks R, Bergmann M, Boeing $H$, Koumantaki $Y$, Palli D, Pala V, Panico S, Tumino R, Vineis P, Buenode-Mesquita HB, FJB V d, van Gils CH, PHM P, Rodriguez L, Gonzalez CA, Sanchez MJ, Chirlaque MD, Barricarte A, Dorronsoro M, Khaw KT, Rodwell SA, Norat T, Romaguera D, Riboli E. Menopausal hormone therapy and risk of colorectal cancer in the European Prospective Investigation into Cancer and Nutrition. Int J Cancer. 2011;128(8):1881-9.

31. Park SY, Wilkens LR, Kolonel LN, Henderson BE, Le Marchand L. Inverse associations of dietary fiber and menopausal hormone therapy with colorectal cancer risk in the multiethnic cohort study. Int J Cancer. 2016; 139(6):1241-50

32. Ciardiello F, Normanno N, Martinelli E, Troiani T, Pisconti S, Cardone C, Nappi A, Bordonaro AR, Rachiglio M, Lambiase M, Latiano TP, Modoni G, Cordio S, Giuliani F, Biglietto M, Montesarchio V, Barone C, Tonini G, Cinieri S, Febbraro A, Rizzi D, De Vita F, Orditura M, Colucci G, Maiello E, Investigators C-G. Cetuximab continuation after first progression in metastatic colorectal cancer (CAPRI-GOIM): a randomized phase II trial of FOLFOX plus cetuximab versus FOLFOX. Ann Oncol. 2016;27(6):1055-61.

33. Bridgewater J, Adam R, Chau I, Alfonso PG, Rivoire M, Lasserre S, Loeffler M, Gruenberger T. Updated efficacy/safety findings from a randomized, phase 2 study of bevacizumab plus mFOLFOX6 or FOLFOXIRI in patients with initially unresectable liver metastases from colorectal cancer (OLIVIA study). Eur J Cancer. 2013;49:S483-S4.

34. Price TJ, Zannino D, Wilson K, Simes RJ, Cassidy J, Van Hazel GA, Robinson BA, Broad A, Ganju V, Ackland SP, Tebbutt NC. Bevacizumab is equally effective and no more toxic in elderly patients with advanced colorectal cancer: a subgroup analysis from the AGITG MAX trial: an international randomised controlled trial of Capecitabine, Bevacizumab and Mitomycin C. Ann Oncol. 2012;23(6):1531-6.

35. Rudolph A, Sainz J, Hein R, Hoffmeister M, Frank B, Forsti A, Brenner H, Hemminki K, Chang-Claude J. Modification of menopausal hormone therapy-associated colorectal cancer risk by polymorphisms in sex steroid signaling, metabolism and transport related genes. Endocr Relat Cancer. 2011;18(3):371-84.

36. Johnson JR, Lacey JV, Lazovich D, Geller MA, Schairer C, Schatzkin A, Flood A. Menopausal hormone therapy and risk of colorectal Cancer. Cancer Epidemiol Biomark Prev. 2009;18(1):196-203.
37. Yang $Q$, Yin CX, Liao FX, Huang YY, He WZ, Jiang C, Guo GF, Zhang B, Xia LP. Bevacizumab plus chemotherapy as third- or later-line therapy in patients with heavily treated metastatic colorectal cancer. Onco Targets Ther. 2015:8:2407-13.

38. Kemeny NE, Jarnagin WR, Capanu M, Fong YM, Gewirtz AN, DeMatteo RP, D'Angelica MI. Randomized phase II trial of adjuvant hepatic arterial infusion and systemic chemotherapy with or without Bevacizumab in patients with resected hepatic metastases from colorectal Cancer. J Clin Oncol. 2011;29(7): 884-9.

39. Moosmann N, Laessig D, Michaely HJ, Schulz C, Heinemann V. Effective second-line treatment with cetuximab and bevacizumab in a patient with hepatic metastases of colorectal cancer and hyperbilirubinemia. Onkologie. 2007;30(10):509-12.

\section{Publisher's Note}

Springer Nature remains neutral with regard to jurisdictional claims in published maps and institutional affiliations.

\section{Ready to submit your research? Choose BMC and benefit from:}

- fast, convenient online submission

- thorough peer review by experienced researchers in your field

- rapid publication on acceptance

- support for research data, including large and complex data types

- gold Open Access which fosters wider collaboration and increased citations

- maximum visibility for your research: over $100 \mathrm{M}$ website views per year

At BMC, research is always in progress.

Learn more biomedcentral.com/submissions 